\title{
Agriculture and Biodiversity: Production with Sustainability
}

\author{
Marcio Moacir Bessa*1 and Matheus Vinicius Abadia Ventura ${ }^{2}$ \\ ${ }^{1}$ Paulista State University, Brazil \\ ${ }^{2}$ Goiano Federal Institute, Brazil
}

*Corresponding author: Marcio Moacir Bessa, Postgraduate in Geography, Paulista State University, Marilia, Brazil

\begin{abstract}
ARTICLE INFO
Received: March 25, 2019

Published: 幽 April 01, 2019

Citation: Marcio Moacir Bessa, Matheus Vinicius Abadia Ventura. Agriculture and Biodiversity: Production with Sustainability. Biomed J Sci \& Tech Res 16(4)-2019. BJSTR. MS.ID.002885.
\end{abstract}

Keywords: Sustainable; Agroecology; Agroecosystem; Ecosystem

\section{ABSTRACT}

In cooperation with ecology and other sciences, it is used to find solutions to the serious problems that compromise the environment. The state of ecosystems itself cannot be understood beyond its historical evolution. The set of indicators of social equality that are rarely taken into account in this analysis but have a decisive impact on the behavior of others. It was fundamental to understand that agroecosystems are dynamic systems functioning, internal and external influences, as well as similarities. We proceeded to the integration, analysis and discussion of information obtained, trying to draw theoretical and methodological conclusions to contribute to the debate on the future of agriculture today and the necessary ecological conversion, with specific recommendations for the case study, in the city of Ipiranga de Goiás, in the St. Patrick's Valley. In the current conjuncture the results of the research and laborious work included the time to analyze the way of thinking, the form of development of agriculture before the green revolution where it became very interesting, such as agriculture practiced by our ancestors, which was much more sustainable development of what is done today, albeit with a lower level of production. Natural productivity of agricultural systems was greater than at present, also biodiversity, less water consumption and greater equity in the distribution of income to peasants.

\section{Introduction}

In cooperation with ecology and other sciences, it is used to find solutions to the serious problems that compromise the environment. First-order environmental problems such as global warming may not have a clear diagnosis and therefore adequate solutions, if not analyzed with the necessary time perspective. The state of ecosystems itself can't be understood beyond its historical evolution. Its reconstruction is a very useful tool for a correct diagnosis of the environmental conditions and to look for enough solutions. This idea of an applied knowledge, far from a narrative or literary history is are claims, being a practical story built in dialogue with other disciplines. An example of applied history goes through a careful analysis of the sustainability of the different ways in which land was cultivated and agricultural land uses have been distributed over the last 100 years using a battery of indicators that cover all aspects involved. Indicators of economic, energy, agronomic and environmental character, among which it paid special attention to water management and fertility. The set of indicators of social equality that are rarely considered in this analysis but have a decisive impact on the behavior of others. Since such a thorough examination of agricultural systems would be impossible to make a Brazilian scale as an analysis performed as a representative of the environmental, social and economic agroecosystem that compromises the future of the agricultural sector.

\section{Methodology}

To understand how agroecosystems was used a theoretical research tool, whereas methodology was evaluating different agroecosystems on a local and global scale. It was essential to understand that agroecosystems are dynamic systems [1], functioning, internal and external influences, as well as the similarities. Places that meet these qualities are several scattered throughout the Brazilian geography, but not everyone has such a complete and well organized municipal archive, as in the case of 
Ipiranga de Goiás, which can be complemented with supporting documentation available for the municipal historical archive. The study site and its described edaphoclimatic characteristics and the current state of the agroecosystem diagnosed need to be seen, both from the socioeconomic and environmental point of view. For this we have sought the support not only of what they say but also about what they think the farmers themselves do, in view of their development of the agroecosystem throughout the twentieth century. Thanks to archival documents and oral testimony has been able to know how to work the agroecosystem in five different moments as if it were, clearly shown the structural and operational changes that has been brought to the current crisis.

In these factors, direct changes and their consequences are explained and analyzed the assessment of the actual sustainability, whereby an X-ray of the situation, valuing a battery of selected indicators, both based on their utility, such as the possibility of evaluation. We proceeded to the integration, analysis and discussion of the information obtained, trying to draw theoretical and methodological conclusions to contribute to the debate on the future of agriculture today and the necessary ecological conversion, with specific recommendations for the case study, in São Patricio Valley, but valid for the whole local agriculture. This is dedicated to the results of complex and laborious research work included the time are very interesting, as the farming practiced by our elders, which was much more sustainable than is done today, albeit with a lower level of production. Natural productivity of agricultural systems was greater than at present, also biodiversity, less water consumption and greater equity in the distribution of agricultural income.

\section{Results and Discussion}

As a result of the demand for many years, there is a management model designed to achieve maximum profitability, which increases the production on land, even above its load capacity, while saving the subsistence farmers' base. A place where precipitation and temperatures are within the normal range in central-western Brazil, whose soil and climatic conditions are therefore representative, with world-wide crops such as cereals, horticulture, etc. The study also shows that agriculture, contrary to what is happening today and is commonly thought, was to meet basic needs and provided in terms of media superior to that of other non-agricultural incomes in relation to other activities. It is true that basic needs were previously lower and consumption less wasteful, but it seems clear that their growth has promoted more intensive farming systems in many cases, causing deterioration. The great advance of Brazilian agriculture during the 1960s and 1970s was due to the simplification of agroecosystems, both territorially, with monocultures and genetic technologies, reduction of the number of crop varieties and cattle breeds, forcing natural cycles. Such a landmark was named Green Revolution, which is the intensive model of agrochemical use in agriculture [2].

It is easy to see that the problem of hunger has become increasingly serious in various parts of the world, with the great capitalist countries fearing it to become a decisive factor in social tensions in many countries [3]. We had to bring in the energy, water and nutrients needed for acceleration cycles and often fight against harmful chemical damage, pests and diseases, being a design tool for ecological farming systems. However, it does not propose to go back to the past, but to recover these forms of management, they must be applicable today for the design of sustainable agricultural systems, especially for organic farming. In fact, experience in the management and operation of agroecosystems in the past, especially in the use of renewable energy and fertilizers of animal origin, provides useful knowledge to significantly improve the sustainability of Brazilian agriculture and organic farming, in particular with a methodological basis. must do when we analyze heavily anthropolyzed agroecosystems, where there were transformations and severe forms of traditional management and profound practices disappeared, as in the case of agroecosystems in Latin America. When the traditional knowledge and rationality that guides have disappeared, history as a scientific discipline becomes a need to recover and recreate new technological and cultural bases, forms of management that were previously sustainable and the instrument of learning mistakes made over time.

The city of Ipiranga de Goiás has adversities related to the system of milk production [4]. In addition, in the last years we have seen a change in the tasks assigned by agronomists and veterinarians, requiring them to go through an overly fragmentary approach centered on the size of culture, herd or farm, in order to maximize profitability; a systemic approach, focusing on agroecosystem with goals to improve sustainability and promote rural development. This shift in focus requires new theories, methodological tools and knowledge to guide it properly and facilitate sustainable design professionals in agricultural production systems. We can find a concrete proposal made from agroecology as a scientific, methodological and knowledge approach to guide it.

The historical experience has served in this case to suggest improvements in the field of management that in general to design a more sustainable agroecosystem. Among the recommendations included can be highlighted below. First, the promotion of organic farming as a model of sustainable agriculture that is firmly committed to the quality, processing and marketing of its products. But, for that, it can develop in ideal conditions and it is essential, among other things, to ensure a better integration between agriculture and livestock.

For this, we must add actions to recover lost biodiversity. For example, by recovering pastures available to the municipality or by defining biological corridors, some water channels and roads that intersect and confronted with the growing tradition that has dominated Brazil, as well as bet on the diversification of crops, product quality and in other areas, such as fruit growing. Quality should be based not only on the organic production mode, but also on the differentiation of flavors, such as the recovery and use of traditional varieties being essential and hence the biodiversity of 
the system as a whole is enhanced as well. These strategies together reduce costs and increase revenue through organic subsidies. That is, to improve the profitability and net profit of farmers. But in order to get rewarding prices it needs to organize the offer. In this sense, short distribution circuits should be favored in which distribution control is largely in the hands of producers, or because they are markets that are physically close or because they have no intermediaries. But the implementation of these measures not only in effect not contain urban sprawl and the difficulties you are creating for access to land and rejuvenate the age of farmers.

\section{Final Considerations}

In the current conjuncture the results of the research and laborious work included the time to analyze the way of thinking, the form of development of agriculture before the green revolution where it became very interesting, such as agriculture practiced by

\section{ISSN: 2574-1241}

DOI: 10.26717/BJSTR.2019.16.002885

Marcio Moacir Bessa. Biomed J Sci \& Tech Res

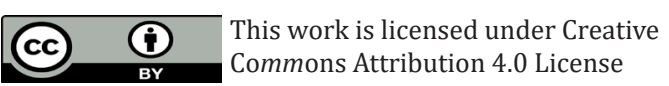

Submission Link: https://biomedres.us/submit-manuscript.php our ancestors, which was much more sustainable development of what is done today, albeit with a lower level of production. Natural productivity of agricultural systems was higher than at present, also biodiversity, lower water consumption and greater equity in the distribution of income to peasants.

\section{References}

1. Bessa MM (2015) The meaning, importance and problems faced by the peasant families, milk producers, in the municipality of ipiranga de goiás (GO). Scientific Multidisciplinary Journal 2(1): 119-129.

2. Carvalho j PL, Silva l M S (2017) Indicators of sustainability in the understanding of the adaptation process of family agroecosystems. Family Farming: Research, Training and Development 11(1): 87-102.

3. Rose a V (1998) Agriculture and the environment. São Paulo: Current 1998.

4. Serra, Mendes MRF, Soares m VDA, Monteiro IP (2016) Green Revolution: reflections on the issue of pesticides. Scientific Journal of the Center for Sustainable Development Studies of UNDB 1(4): 2-25.

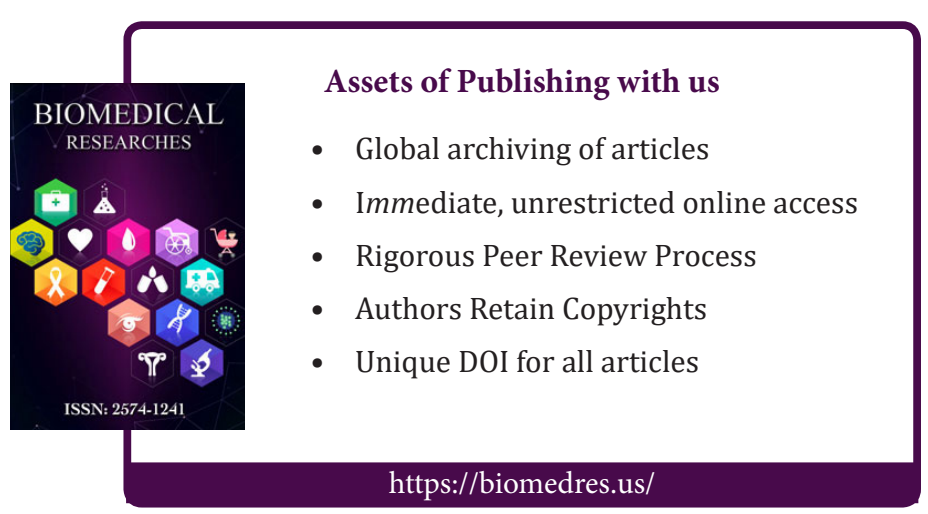

